\title{
Neonatal Exposure to the Dipeptidyl Peptidase-IV Inhibitors Diprotin A and Sitagliptin Induces Depression-Like Behavior, Anxiety, and Latent Aggression in Adolescent and Adult Rats
}

\author{
Nataliya A. Krupina*, Nadezhda N. Khlebnikova \\ Laboratory of the General Pathology of Nervous System, Federal State Budgetary Scientific Institution \\ "Institute of General Pathology and Pathophysiology", Moscow, Russia \\ Email:"krupina-na@yandex.ru
}

Received 4 February 2016; accepted 12 April 2016; published 15 April 2016

Copyright @ 2016 by authors and Scientific Research Publishing Inc.

This work is licensed under the Creative Commons Attribution International License (CC BY). http://creativecommons.org/licenses/by/4.0/

(c) (i) Open Access

\begin{abstract}
Emotional and motivational disorders in adults are often considered to be the result of altered neurodevelopment. Clinical and experimental data provide evidence that serine protease dipeptidyl peptidase-IV (DPP-IV, EC 3.4.14.5) is involved in the pathophysiology of psycho-emotional disorders. Recently, we have shown that adolescent and adult rats exhibit an increase in anxiety and depression-related behaviors after neonatal administration of a synthetic non-competitive inhibitor of DPP-IV, methionyl-2(S)-cyano-pyrrolidine. In the present study, we tested the effects of two competitive, selective DPP-IV inhibitors, sitagliptin $(4 \mathrm{mg} / \mathrm{kg})$ and diprotin $A(2 \mathrm{mg} / \mathrm{kg})$, administered at postnatal days 5 - 18 on the emotional and motivational behavior of adolescent and adult rats. We observed increased anxiety in one-month-old diprotin A- or sitagliptin-treated rats in the elevated plus maze; diprotin A also enhanced the animals' anxiety score using a ranked scale for evaluating anxiety and phobias. In the sucrose consumption and preference test, depressive-like behavior was pronounced in both the diprotin A- and sitagliptin-treated one-month-old animals, while only the diprotin A-treated rats exhibited a decrease in sucrose consumption at the age of 2 months. The diprotin A-treated rats also demonstrated behavioral despair and decreased activity in the forced swimming test within 1 - 3 months of age. Increased aggression was observed in 1 - 3-month-old diprotin A-treated rats and in two-month-old sitagliptin-treated rats. These findings support the hypothesis that DPP-IV is involved in the genesis of emotional and motivational disorders. Additionally, the results show that diprotin A impairs the adolescent and adult rats' behavior more significantly than sitagliptin when the animals were treated with the DPP-IV

"Corresponding author.
\end{abstract}

How to cite this paper: Krupina, N.A. and Khlebnikova, N.N. (2016) Neonatal Exposure to the Dipeptidyl Peptidase-IV Inhibitors Diprotin A and Sitagliptin Induces Depression-Like Behavior, Anxiety, and Latent Aggression in Adolescent and Adult Rats. Journal of Behavioral and Brain Science, 6, 167-183. http://dx.doi.org/10.4236/jbbs.2016.64018 
inhibitors in the early postnatal period.

Keywords

Dipeptidyl Peptidase IV Inhibitors, Rat, Depression, Anxiety, Aggression

\section{Introduction}

The heterogeneous nature of depression is well established [1] [2]. The comorbidity of depressed symptoms with anxiety and aggression (specifically aggression directed towards self) leads to a more severe course of the disease, constitutes an important risk factor for suicide and complicates the treatment [3]-[6]. Of particular interest are the data that the susceptibility to aggression may increase in patients with an altered mood or an anxious state [7].

The neurobiological findings from the studies on depression [1] [8], anxiety [9] and aggression [10]-[12] give rise to the hypotheses that the networks and neurochemical systems mediating depression and aggression, depression and anxiety, anxiety and aggression are related to varying degrees and very likely overlap. Overall, the results do not reach an unambiguous conclusion about the pathogenesis of depression, anxiety and aggression.

Numerous clinical data demonstrate the negative consequences of adverse early-life events in provoking emotional and mood disorders [13]. Experimental studies on modeling behavioral alterations suggest that the brain is strongly sensitive to adverse events at early developmental stages [14]. Rat brain systems responsible for emotional reactions and motivation are formed in the second half of pregnancy and the postnatal period (up to the third - fourth postnatal weeks), when synaptogenesis of the major neurotransmitter systems mediating emotions and mood occurs [15]-[17]. During the same period, the peptidergic neuronal populations that express neuropeptides which play a substantial role in the central regulation of affective behaviors [18] are formed within particular hypothalamic areas [19].

Although increasing evidence proves the involvement of neuropeptides in the development of depression and anxiety, there is still a lack of data on the enzymes that cleave neuropeptides, particularly the peptides enriched in proline residues. The unique conformation of the prolyl bond protects the peptides from degradation [20]; thus, there is much interest in the proteases that cleave this bond. Clinical studies have shown changes in the activities of the proline-specific serine proteases dipeptidyl peptidase-IV (DPP-IV; CD 26; EC 3.4.14.5) and prolyl endopeptidase (PEP; EC 3.4.21.26) in the blood of the patients with symptoms of anxiety and depression [21] [22]. The proposed involvement of these proteases in the genesis of mental disorders has received an additional confirmation in experimental studies. Mice with a targeted inactivation of the DPP-IV gene exhibited an antidepressant-like and hyperactive phenotype [23]. DPP-IV-deficient rats demonstrated anxiolytic-like behavior and reduced stress-like responses [24]. In our studies, we have revealed increased activities of both DPP-IV and PEP in several brain structures in rat models of stress-induced depression-like state and experimental depressive-like syndrome associated with a dopamine deficit induced by the proneurotoxin 1-methyl-4-phenyl-1,2,3,6-tetrahydropyridine [25] [26].

To further study of the contribution of one of the peptidases-DPP-IV in the development of behavioral disturbances, we have recently applied a different approach, which is based on inhibiting of the enzyme in the early postnatal period. Kato T. et al. [27] observed developmental changes in X-prolyl DPP activity in the postnatal rat brain between day 4 and week 4, namely an increase in the total enzyme activity per brain. The total DPP activity was the highest at three and four weeks and then decreased; the specific activity of the enzyme per mg protein in young rat brain was also higher than that in the adult brain. The authors suggested that the X-prolyl DPP activity in the rat brain might be related to the development of the nervous system. Brust et al. [28] showed an increase in the activity of the membrane-bound serine peptidase DPP-IV in brain homogenates of 1 - 4week-old Wistar rats. Based on these observations, we determined that rats exposed to a synthetic non-competitive irreversible inhibitor of DPP-IV, methionyl-2(S)-cyano-pyrrolidine, for two weeks after birth on postnatal days 5 - 18 demonstrated increased anxiety- and depression-related behaviors in adolescence and adulthood [29]. The behavioral alterations were associated with latent aggression [30] and with increased DPP-IV and PEP activity in some brain regions [31]. 
DPP-IV is a multifaceted enzyme, with specificity for unique substrates, such as neuropeptide $Y$, substance $P$, peptide YY, endomorphins, a large family of chemokines that are important in the immune system functions, and hormonal peptides belonging to the glucagon superfamily, including glucagon-like peptide-1 [32]. An important practical motive for studying the putative contribution of this enzyme to the occurrence of behavioral deficits is based on the fact that DPP-IV inhibitors, which have pleiotropic effects, are widely used in the clinic. For example, gliptins are now widely used to improve postprandial glycemic control in patients with type 2 diabetes by enhancing the incretin effect of glucagon-like peptide- 1 and glucose-dependent insulinotropic peptide [33]. Another DPP-IV inhibitor, diprotin A, has been shown to enhance hematopoietic stem cell engraftment in murine transplantation models and has been evaluated in clinical settings for its influence on the engraftment of cord blood cells [34]. However, it is unclear whether these DPP-IV inhibitors are related to behavioral deficit and emotional health.

With this in mind, the current study was performed to compare the consequences of postnatal administration of two well-known competitive DPP-IV inhibitors, sitagliptin and diprotin A, on the emotional and motivational behavior of adolescent and adult rats. We evaluated the animals' emotional and behavioral disturbances by testing their depression-like behavior, anxiety and social interactions in ontogenesis from 1 to 6 months of age. Additionally, we tested the hypothesis that postnatal modulation of DPP-IV activity may trigger the occurrence of long-lasting behavioral disorders.

\section{Material and Methods}

\subsection{Animals}

The experiments were performed on 59 male Wistar rats (nursery of the Institute of General Pathology and Pathophysiology). The animals were housed in groups of $4-7$ (each from the same litter) in standard clear plastic cages $(37 \times 57 \times 19 \mathrm{~cm})$ under a natural light/dark cycle, with water and food available ad libitum (except during the sucrose consumption and preference test). All procedures were performed in accordance with the EU Directive 2010/63/EU on the protection of animals used for scientific purposes adopted on September 22, 2010, the Rules of Laboratory Practice in the Russian Federation (Order of the Ministry of Health Care and Social Development of the Russian Federation № 708n of 23.08.2010), and approved by the Ethics Committee of the Institute of General Pathology and Pathophysiology. All behavioral testing occurred between 11:00 and 18:00 hrs.

\subsection{Drugs and Treatment}

The DPP-IV inhibitors were intraperitoneally administered to the male Wistar rat pups on postnatal days 5 - 18 (for 14 days) once daily at $0.1 \mathrm{ml}$ per $10 \mathrm{~g}$ body weight. Freshly prepared solutions of the DPP-IV inhibitors in saline were used.

Sitagliptin (phosphate monohydrate, MW 523.32) was purchased from Sigma-Aldrich (USA). The approved maximum daily dose of sitagliptin in the clinic is $100 \mathrm{mg}$; the experimental rats received a sitagliptin dose of 4 $\mathrm{mg} / \mathrm{kg}$ per day $(\mathrm{n}=22)$ that corresponded to approximately half of the maximum daily dose for humans [35]. Diprotin A (H-Ile-Pro-Ile-OH, MW 341.45) was purchased from Sigma-Aldrich (USA). In addition to its potential use in the clinic (see 1 , the bold numbers throughout the text refer to a particular section of the manuscript), diprotin A is a reference standard inhibitory compound for testing new inhibitors of DPP-IV. The experimental rats received diprotin A at a dose of $2 \mathrm{mg} / \mathrm{kg}$ a day $(\mathrm{n}=17)$, which was an approximately equimolar amount of sitagliptin. The control rats $(n=19)$ were injected with saline. Each group consisted of pups from 3 - 4 litters.

\subsection{Behavioral Testing}

The rats were weighed monthly and subjected to behavioral testing at the ages of one, two, three, and six months. The battery of tests included the elevated plus maze (EPM) (see 2.3.1.), forced swimming test (FST) (see 2.3.2.), anxiety-phobic score (AFS) evaluation (see 2.3.3.), sucrose consumption and preference (SCP) test (see 2.3.4.), and social contact (SC) test (see 2.3.5.). In the majority of the tests, half of the animals in each group were examined on the first day and the other half were examined on the second day (Table 1). Thus, each rat had at least one day off between tests, with the exception of the SC and SCP tests. The SC test was performed on the third and fourth days of the SCP test, when the rats were singly housed. The complete examination at each time 
Table 1. A timeline of the monthly behavioral testing.

\begin{tabular}{ccc}
\hline Days of testing & Tests & Number of rats \\
\hline Days 1 - 2 & Elevated Plus Maze & A day-off \\
Day 3 & Forced swimming test & A half of each group a day \\
Days 4 - 5 & Evaluation of anxiety-phobic score & A half of each group a day \\
Days 6 - 7 & Adaptation to single housing and stabilization of the consumption level & All the animals \\
in sucrose consumption/preference test & Sucrose consumption/preference test & All the animals \\
Days $10-11-12$ & Social contact test & A half of each group a day \\
Days $10-11$ & &
\end{tabular}

point lasted approximately two weeks.

Upon completion of behavioral testing at the age of three months, some of the animals in each group were decapitated using a guillotine, and the brain structures were isolated and frozen in liquid nitrogen for subsequent biochemical and genetic analysis (data not shown). As a result, at the age of 6 months, there were fewer animals in each group: diprotin A ( $n=9)$, sitagliptin $(n=15)$, and control $(n=11)$.

\subsubsection{Elevated Plus Maze}

The EPM is utilized to assess anxiety and exploration [36]. A VideoMot2 System (TSE System, Germany) was used. The EPM consisted of four arms arranged in the shape of cross: two opposing arms with 2 side walls and an end wall (length $\times$ width $\times$ height: $43 \times 14 \times 22 \mathrm{~cm}$ ) (closed arms) and 2 additional arms without walls (length $\times$ width: $43 \mathrm{~cm} \times 14 \mathrm{~cm}$ ) (open arms). The EPM was elevated $70 \mathrm{~cm}$ off the ground. The illumination over the central zone of the maze $(14 \times 14 \mathrm{~cm})$ was 24 Lux. The rats were placed in the center of the maze facing one of the open arms. The test session lasted for $5 \mathrm{~min}$. The maze was cleaned with ethanol after each session. The number of entries and the time (s) spent in the open and closed arms were recorded. The animals' preference for the open arms was calculated as a ratio of open arm entries to the total number of entries into both the open and closed arms (\%). To increase the sensitivity of the test, we also estimated the animals' exploration, risk-assessment behavior, and emotional responses using the number and the latency to engage in vertical rearing postures, head dipping over the open arms and grooming episodes, respectively. Although head dipping and grooming may not provide unequivocal measures of anxiety [37], we share the idea that an increased number of head dips is associated with a decrease in anxiety [38], and grooming measures may help to evaluate anxiety-like behaviors [39]. We also used total distance traveled in all of the regions of the EPM as an index of locomotor activity in the test.

\subsubsection{Forced Swimming Test}

Unlike Porsolt's original FST [40], where the rats are trained to learn an immobility response on the first exposure and demonstrate increased immobility on the second exposure one day later, we used a single exposure in this test. Previous studies [41] have shown that this modification of the test is suitable to reveal depressive-like behaviors in rats and avoids errors in the interpretation associated with the possible interference of learning. In addition, we have shown [42] that a single exposure is more informative than a repeated test to detect a previously existing depressive-like state in rats because the preliminary testing itself produces a depression-like effect that can complicate the interpretation of the data. The FST was performed in a cylindrical plastic tank (height $47 \mathrm{~cm}$ and internal diameter $35 \mathrm{~cm}$ ) filled with water to a depth of $35 \mathrm{~cm}$. The water temperature was maintained at $25^{\circ} \mathrm{C} \pm 1^{\circ} \mathrm{C}$. Each of the rats was forced to swim for $10 \mathrm{~min}$. The amount of time each animal engaged in active swimming (strong movements of all four limbs, often with the front limbs breaking the surface of the water, climbing or scratching the wall, and jumping), passive swimming (only the movements necessary to keep the head above the surface of the water, usually weak movements of one of the hind limbs; corresponds to the immobility described by Porsolt) and immobility (floating vertically in the water without any swimming movements) were measured. Our study was based on a biorhythmologic approach to evaluating forced swimming [43]. The authors who created this approach have shown that rats with induced behavioral depression exhibit a reorganization of their swimming rhythms, namely an increase in the number of short cycles of immobil- 
ity (less than 6 s). They describe the so-called chrono-biological "index of depression" (ID) as a ratio of the number of short episodes of immobility to the total number of episodes of active swimming, and showed that the ID expressed behavioral depression more exactly than the usual registration of immobility time. Thus, we recorded the number of episodes of active swimming and short immobility to calculate the ID. A longer the duration of immobility and higher ID indicated that the rats exhibited more depression-like symptoms.

\subsubsection{Anxiety-Phobic Score}

The anxiety-phobic state was evaluated using a method based on a ranked scale consisting of parameters that characterize the species-specific responses of a rat to a series of nine mild test stimuli that induce anxiety and fear [44]. The tests are based on two fundamental situations to provoke anxiety and phobia in rats: 1) approaching an unfamiliar inanimate object or situation and 2) the response to stroking and the approach of the experimenter's hand. Comprehensive testing is performed in the open field. The rats' responses are assigned a score from 0 to 3 points in each test. At the end of the examination, the total anxiety-phobic score is calculated for each animal. A higher score corresponds to a higher level of anxiety and phobia. The animals are not habituated to the test procedure when they are tested at intervals of $4-7$ days.

\subsubsection{Sucrose Consumption and Preference Test}

In this test, the rats were placed in individual standard clear plastic cages $(36.5 \mathrm{~cm} \times 20.5 \mathrm{~cm} \times 14 \mathrm{~cm})$ and were provided dry food for four days. The animals were not subjected to food or water deprivation before the test. During the test, each rat was presented with two bottles, one containing tap water and the other containing a $10 \%$ sucrose solution. The positions of the bottles were alternated every day to prevent the development of side bias. After two days for adaptation to the chamber and stabilization of the consumption level, the quantities of sucrose (g) and water intake was measured as the difference in the weight (g) of the corresponding bottle every morning for three days. The daily liquid intake (sucrose plus water) was calculated. Sucrose preference (\%) was calculated as the percentage of sucrose solution consumption out of the daily liquid intake. The relative sucrose consumption (a percent of the body weight, \%) was also calculated. Reduced liquid consumption reflects a decrease in drinking motivation; reduced sucrose consumption indicates the development of anhedonia, a reliable measure of the depression-like state [45]. We calculated the averages for each indicator over the three days.

\subsubsection{Social Contact Test}

The social interaction task was performed in an unfamiliar Plexiglas test cage $(37 \times 57 \times 19 \mathrm{~cm})$ located in an experimental room with indirect red light intensity set at 7 lux above the center of the cage. The floor of the cage was not covered with sawdust, and the cage was deodorized after each test. We assessed contacts between pairs of control or experimental unfamiliar weight-matched males from different litters. The rats were singly housed for two days before testing. Social exploration was observed for $15 \mathrm{~min}$. We calculated the total frequency and duration of non-aggressive and aggressive social contacts. The behaviors that represented non-aggressive social contacts included sniffing, social grooming, crawling under or over the partner and following with non-aggressive contact; the behaviors that represented aggressive social contact included following with aggressive contact, attacks, aggressive grooming, biting, and fights.

\subsection{Statistical Analysis}

The statistical analyses were performed using STATISTICA 7.0 for Windows. When the data met the requirements for parametric statistics, the overall effect was first analyzed by a mixed two-way analysis of variance with the treatment as the between-subject factor and the animals' age as the within-subject factor (repeated measures factor). The six-month-old rats were excluded from the analysis of the within-subject factor effects because there were fewer animals in each group at this time point. The differences between or within groups were evaluated using parametric one-way ANOVA or repeated measures ANOVA followed by the NewmanKeuls post hoc test. When the data did not meet the requirements for parametric statistics, a nonparametric Kruskal-Wallis ANOVA or Freidman ANOVA was employed to evaluate the between and within group effects, respectively. They were followed by a multiple comparisons analysis of the mean ranks and the Wilcoxon matched pairs test with False Discovery Rate (FDR) control [46] to correct for multiple comparisons. The data are given as the means \pm SEM (standard error of the mean). The $\alpha$ level was set at 0.05 . 


\section{Results}

The two-way ANOVA showed a significant age effect $(\mathrm{F}=4139.820 ; \mathrm{p}<0.001)$, treatment effect $(\mathrm{F}=11.000$; $\mathrm{p}<0.001)$ and age $\mathrm{x}$ treatment interaction $(\mathrm{F}=6.553$; $\mathrm{p}<0.001)$. Repeated measures ANOVA showed that the animals' weights increased from month 1 to month 3 in the experimental and control groups ( $p<0.001$ in all cases).

The body weights of the postnatal day 5 rats (the day of the first injection) did not differ between the experimental and control groups. One-way ANOVA revealed a difference in the weights of the one-month-old $[\mathrm{F}(2,56)=10.864, \mathrm{p}<0.001]$, two-month-old $[\mathrm{F}(2,56)=10.962, \mathrm{p}<0.001]$, and three-month-old rats $[\mathrm{F}(2,56)=$ 7.154, $\mathrm{p}<0.01$ ]. The results of the between groups post hoc analysis are shown in Figure 1 . At the ages of one, two, and three months, the sitagliptin-treated rats weighed less than the control and diprotin A-treated rats (Figure 1). At the age of six months, there were no significant differences between the treated and control animals.

\subsection{Effects of Neonatal Diprotin A and Sitagliptin Exposure on Rats' Behavior in the Elevated Plus Maze}

Most of the effects of the DPP-IV inhibitors on anxiety and exploratory behavior in the EPM were observed in 1-month-old rats. According to the Kruskal-Wallis ANOVA, the experimental rats exhibited an increased number of closed arm entries [H $(2, \mathrm{~N}=59)=6.598, \mathrm{p}<0.04]$ and a slightly decreased preference for the open arms $[\mathrm{H}(2, \mathrm{~N}=59)=6.442, \mathrm{p}<0.04]$. The results of post hoc analysis are shown in Figure 2. The sitagliptin-treated rats exhibited an increased latency to head dips compared to the controls $[\mathrm{H}(2, \mathrm{~N}=55)=6.515, \mathrm{p}<0.04]$ (Figure 2). We did not observe a difference in the time spent in both the open $[\mathrm{H}(2, \mathrm{~N}=59)=1.110, \mathrm{p}=0.574]$ and closed $[\mathrm{H}(2, \mathrm{~N}=59)=0.085, \mathrm{p}=0.959]$ arms or in the number of head dips $[\mathrm{H}(2, \mathrm{~N}=59)=0.795, \mathrm{p}=$ 0.672 ] by the one-month-old experimental and control rats.

We did not observe the signs of anxiety in the two- and three-month-old rats. In the six-month-old diprotin A-treated rats, the Kruskal-Wallis ANOVA revealed an increase in the time spent in the closed arms $[\mathrm{H}(2, \mathrm{~N}=$ $35)=11.313, \mathrm{p}<0.01$ ]: $284.2 \pm 4.1 \mathrm{~s}$ in the diprotin-treated animals vs. $249.0 \pm 9.3 \mathrm{~s}$ in the controls $(\mathrm{p}=0.042)$ and $217.7 \pm 17.1 \mathrm{~s}$ in the sitagliptin-treated group $(\mathrm{p}=0.003)$, respectively.

The analysis of the animals' exploratory activity and grooming behavior in the EPM are shown in Table 2. The number of vertical rearing postures was increased $[\mathrm{H}(2, \mathrm{~N}=58)=6.015, \mathrm{p}<0.05]$ and the latency to the first posture was decreased $[\mathrm{H}(2, \mathrm{~N}=58)=7.020, \mathrm{p}<0.03]$ in the two-month-old diprotin A-treated rats compared to the controls. In this group, the Friedman ANOVA showed that there were no significant changes in the number of vertical rearing postures throughout the examination [Chi-squared test $(\mathrm{N}=17, \mathrm{df}=2)=4.277, \mathrm{p}>$

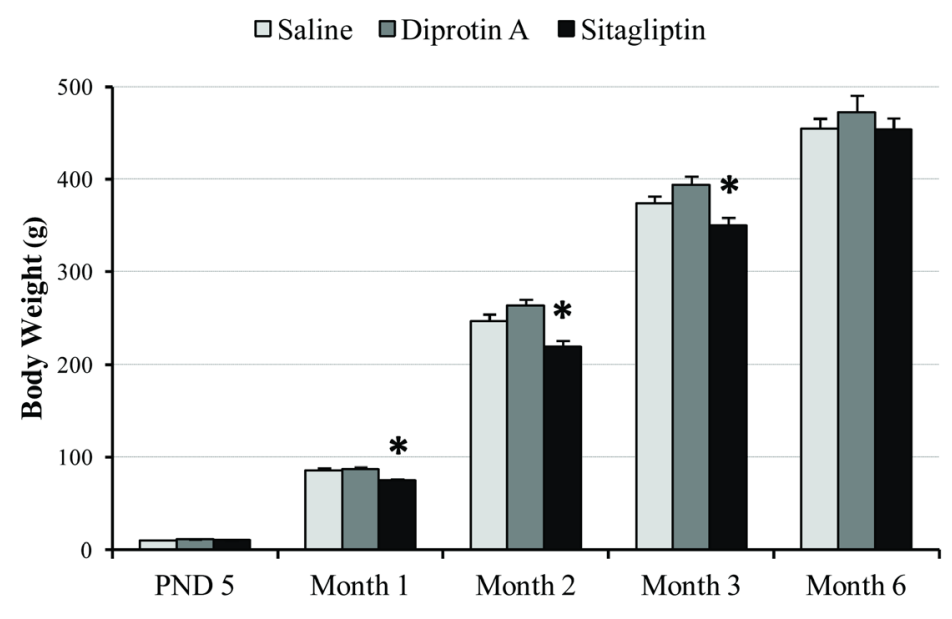

Figure 1. Body weight gain in the diprotin A- and sitagliptin-treated rats compared to the controls. PND 5-postnatal day 5. The * indicates a statistically significant difference from the control (saline-treated) and diprotin A-treated groups, $\mathrm{p}<0.05$ (one way ANOVA followed by the NewmanKeuls post hoc test). 


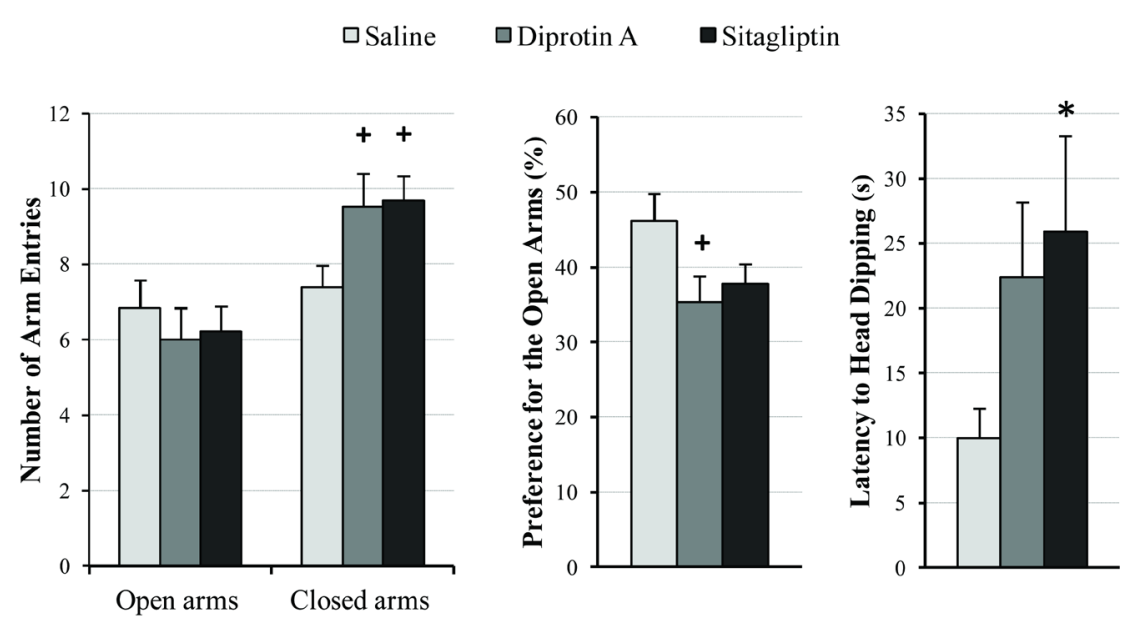

Figure 2. Effects of the DPP-IV inhibitors diprotin A and sitagliptin on the behavior of one-month-old rats in the Elevated Plus Maze test. The ${ }^{*}$ indicates a statistically significant difference compared to the controls (saline-treated), $\mathrm{p}<0.05$; the + indicates $\mathrm{p}<0.09$ compared to the controls (Kruskal-Wallis ANOVA followed by post hoc multiple comparisons analyses of the mean ranks).

Table 2. Effects of DPP-IV inhibitors diprotin A and sitagliptin on the rats' exploratory activity and grooming in the Elevated Plus Maze at different time points.

\begin{tabular}{|c|c|c|c|c|c|c|c|c|}
\hline \multirow{3}{*}{ Groups } & \multicolumn{8}{|c|}{ Vertical rearing postures } \\
\hline & \multicolumn{2}{|c|}{ One month } & \multicolumn{2}{|c|}{ Two months } & \multicolumn{2}{|c|}{ Three months } & \multicolumn{2}{|c|}{ Six months } \\
\hline & Number & Latency, s & Number & Latency, s & Number & Latency, s & Number & Latency, s \\
\hline Diprotin A & $11.0 \pm 1.2$ & $43.5 \pm 7.7$ & $11.5 \pm 1.0^{*}$ & $15.9 \pm 2.9^{* \wedge}$ & $8.4 \pm 1.0$ & $31.5 \pm 11.4$ & $3.7 \pm 0.6$ & $35.9 \pm 20.3$ \\
\hline Sitagliptin & $10.7 \pm 0.8$ & $38.5 \pm 5.3$ & $10.3 \pm 1.3$ & $18.6 \pm 3.4^{+\wedge}$ & $8.6 \pm 1.4$ & $29.7 \pm 9.8$ & $10.4 \pm 1.1$ & $22.5 \pm 4.6$ \\
\hline \multirow[t]{3}{*}{ Saline } & $9.0 \pm 1.0$ & $42.3 \pm 6.4$ & $7.7 \pm 1.1$ & $30.5 \pm 6.6$ & $8.9 \pm 0.9$ & $22.8 \pm 6.0$ & $6.1 \pm 1.0$ & $16.8 \pm 5.1$ \\
\hline & \multicolumn{8}{|c|}{ Grooming } \\
\hline & Number & Latency, s & Number & Latency, s & Number & Latency, s & Number & Latency, s \\
\hline Diprotin A & $2.5 \pm 0.6$ & $141.5 \pm 18.5$ & $6.3 \pm 0.8^{\wedge}$ & $73.9 \pm 8.8^{* \# \wedge}$ & $4.8 \pm 1.0$ & $86.5 \pm 14.8^{\wedge}$ & $3.0 \pm 1.3$ & $100.5 \pm 19.1$ \\
\hline Sitagliptin & $4.6 \pm 0.7$ & $110.0 \pm 18.1$ & $7.2 \pm 0.9^{*}$ & $68.5 \pm 10.6^{*}$ & $5.1 \pm 0.9^{*}$ & $92.3 \pm 13.1$ & $4.5 \pm 1.2$ & $139.9 \pm 19.5$ \\
\hline Saline & $2.8 \pm 0.7$ & $128.8 \pm 14.4$ & $4.3 \pm 0.7$ & $126.1 \pm 14.3$ & $2.4 \pm 0.5$ & $119.9 \pm 16.8$ & $2.1 \pm 0.7$ & $155.9 \pm 15.7$ \\
\hline
\end{tabular}

The ${ }^{*}$ indicates statistically significant difference from the control group (saline-treated rats), $\mathrm{p}<0.05$; the ${ }^{\#}$ indicates statistically significant difference from the sitagliptin-treated group, $\mathrm{p}<0.05$; the ${ }^{+}$indicates $\mathrm{p}=0.086$ compared to the controls (Kruskal-Wallis ANOVA followed by post hoc multiple comparisons analyses of the mean ranks). The ${ }^{\wedge}$ indicates statistically significant difference from the values in the same group at the age of one month, $\mathrm{p}<0.033$ (Freidman ANOVA followed by Wilcoxon matched pairs test with FDR control). Values are given as mean \pm SEM (standard error of the mean).

0.05]; however, there was a confirmed decrease in the latency to the first posture in the two-month-old rats [Chi-squared test $(\mathrm{N}=17, \mathrm{df}=2)=9.294, \mathrm{p}=0.010]$. The Friedman ANOVA also revealed a significant decrease in the latency to the first vertical posture [Chi-squared test $(\mathrm{N}=21, \mathrm{df}=2)=8.667, \mathrm{p}=0.013$ ] in the two-month-old sitagliptin-treated rats.

The number of grooming episodes was increased in the two-[H $(2, \mathrm{~N}=58)=6.394, \mathrm{p}<0.05]$ and threemonth-old sitagliptin-treated rats $[\mathrm{H}(2, \mathrm{~N}=58)=6.291, \mathrm{p}<0.05]$ compared to the controls. However, compared to the one-month-old animals from the same group, the number of grooming episodes was not significantly increased, according to the Friedman ANOVA [Chi-squared test $(\mathrm{N}=21, \mathrm{df}=2)=1.506, \mathrm{p}>0.05$ ]. According to the Kruskal-Wallis ANOVA, the two-month-old rats in both experimental groups exhibited a reduced latency to the first grooming episode $[\mathrm{H}(2, \mathrm{~N}=55)=13.090, \mathrm{p}<0.01]$ compared to the controls. In the diprotin A-treated group, an analysis of the dynamics of the latency to the first grooming episode confirmed that the values were decreased in the two- and three-month-old rats [Chi-squared test $(\mathrm{N}=11, \mathrm{df}=2)=9.455, \mathrm{p}=0.009$ ] The decreased latency in the sitagliptin-treated group was not significant [Chi-squared test $(\mathrm{N}=18, \mathrm{df}=2)=$ 2.333, $\mathrm{p}>0$. 05]. The results of the post hoc analysis are shown in Table 2. 
The total distance traveled in all regions of the EPM decreased with age in the experimental and control groups $(\mathrm{F}=78.466, \mathrm{p}<0.001)$. However, there were no significant differences between the experimental and control groups at any age $(\mathrm{F}=1.488, \mathrm{p}>0.05)$.

\subsection{Effects of Neonatal Diprotin A and Sitagliptin Exposure on Rats' Behavior in the Forced Swimming Test}

A two-way ANOVA showed a main effect of treatment $(F=5.328 ; \mathrm{p}<0.01)$ and age $(\mathrm{F}=52.156 ; \mathrm{p}<0.001)$ on the amount of time the animals engaged in active swimming and a main effect of age $(F=29.477 ; p<0.001)$ on the amount of time engaged in passive swimming. There was no treatment $x$ age interaction in either case.

Only the diprotin A-treated rats exhibited depressive-like behaviors in the FST. According to the one-way ANOVA, the one-month-old rats exhibited a decrease in the amount of time spent in active swimming $[\mathrm{F}(2,56)=$ 4.788, $\mathrm{p}<0.02]$ and an increase in the amount of time spent in passive swimming $[\mathrm{F}(2,56)=4.767, \mathrm{p}<0.02]$. The results of the post hoc analysis are shown in Figure 3(a) and Figure 3(b) (respectively). The threemonth-old rats also exhibited a decrease in the amount of time spent in active swimming $[\mathrm{F}(2,56)=4.891, \mathrm{p}<$ $0.02]$ and an increase in the amount of time spent in passive swimming $[F(2,56)=3.458, p<0.04]$, thus retaining the signs of depression-like behaviors. The dynamics of the swimming time were similar in all of the groups, namely, the duration of active swimming decreased with age (repeated measures ANOVA, $p<0.001$ in all cases). In contrast, the duration of passive swimming increased ( $p<0.001$ in sitagliptin- and saline-treated groups; $\mathrm{p}<0.02$ in diprotin-treated group). However, the changes in the diprotin-treated group developed more smoothly.

According to the Kruskal-Wallis ANOVA, the immobility time $[\mathrm{H}(2, \mathrm{~N}=58)=10.354, \mathrm{p}<0.01]$ and ID $[\mathrm{H}$

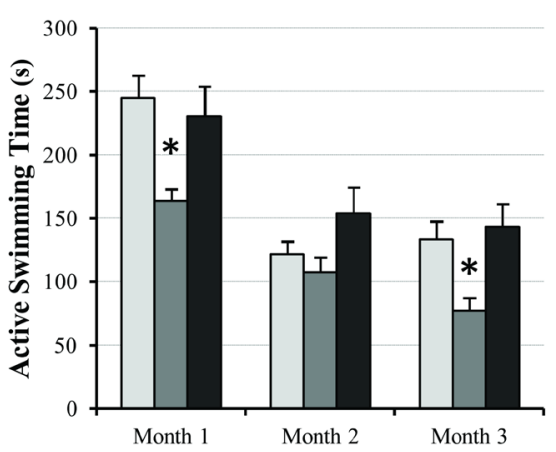

(a)

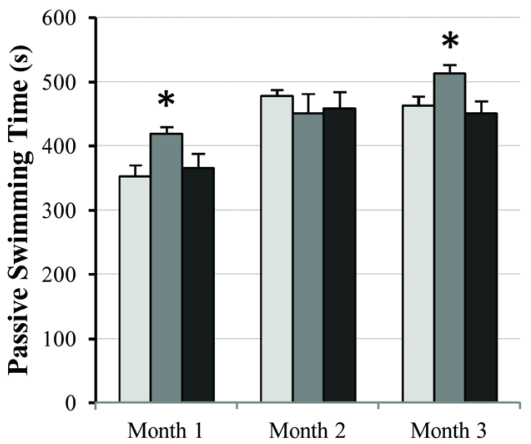

(b)

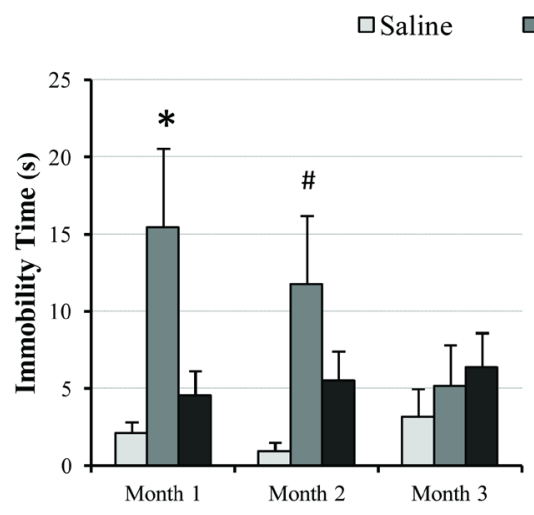

(c)

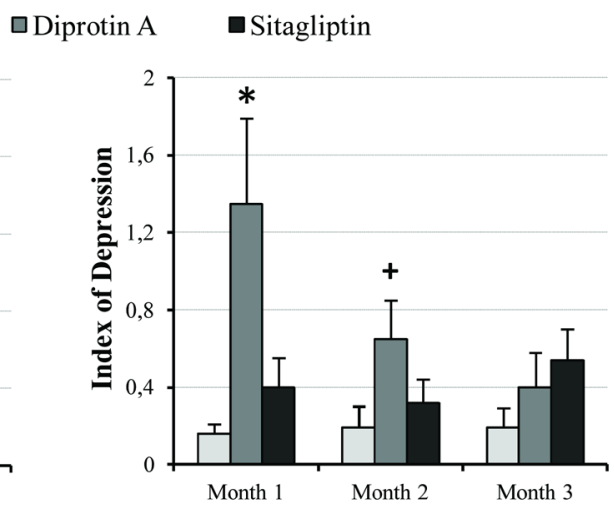

(d)

Figure 3. Effects of postnatally administered diprotin A and sitagliptin on the animals' behavior in the Forced Swimming Test. The ${ }^{*}$ indicates a statistically significant difference compared to the controls (saline-treated), $\mathrm{p}<0.05$; the ${ }^{\#}$ indicates $\mathrm{p}=0.055$, and the ${ }^{+}$indicates $\mathrm{p}<0.1$ compared to the controls. (a) - (c) One way ANOVA followed by the Newman-Keuls post hoc test; (d) Kruskal-Wallis ANOVA followed by post hoc multiple comparisons analyses of the mean ranks. 
$(2, \mathrm{~N}=58)=11.388, \mathrm{p}<0.01]$ of the one-month-old diprotin A-treated rats were increased compared to the controls (Figure 3(c) and Figure 3(d)). The increased ID was due to an increased number of short episodes of immobility $[\mathrm{H}(2, \mathrm{~N}=58)=10.866, \mathrm{p}<0.01]$, which was $8.4 \pm 2.3$ in the diprotin A-treated rats, $3.0 \pm 1.0$ in the sitagliptin-treated rats, and $1.4 \pm 0.5$ in the controls. The immobility time and ID remained elevated in the twomonth-old rats $[\mathrm{H}(2, \mathrm{~N}=58)=7.734, \mathrm{p}<0.03$, and $\mathrm{H}(2, \mathrm{~N}=58)=7.829, \mathrm{p}=0.02$, respectively $]$ and did not differ from the controls at three months. We failed to reveal any changes in the FST in the six-month-old rats.

\subsection{Evaluation of the Anxiety-Phobic Scores in Rats Using the Ranked Scale}

The AFS only differed in the one-month-old rats $[\mathrm{F}(2,56)=5.218, \mathrm{p}<0.01$, one way ANOVA]. The diprotin A-treated rats demonstrated a higher anxiety and phobia score, $7.0 \pm 0.6$ compared to $5.1 \pm 0.6$ in the controls ( $\mathrm{p}=$ 0.026, Newman-Keuls post hoc test). The diprotin A-treated rats were also more anxious than the sitagliptintreated animals, which had an average score of $4.3 \pm 0.6(\mathrm{p}=0.006)$.

\subsection{Effects of Neonatal Diprotin A and Sitagliptin Exposure on Rats' Behavior in the Consumption and Sucrose Preference Test}

In this test, the depressive-like behavior differed between the experimental groups. The one-month-old animals treated with either diprotin $\mathrm{A}$ or sitagliptin demonstrated a decrease in sucrose preference $[\mathrm{H}(2, \mathrm{~N}=59)=$ 15.643, $\mathrm{p}<0.001$ ], relative sucrose consumption [H $(2, \mathrm{~N}=59)=15.984, \mathrm{p}<0.001]$ and daily liquid intake [H $(2, \mathrm{~N}=59)=9.580, \mathrm{p}<0.01]$. Figure 4 shows the results of a post hoc analysis. Only the two-month-old rats
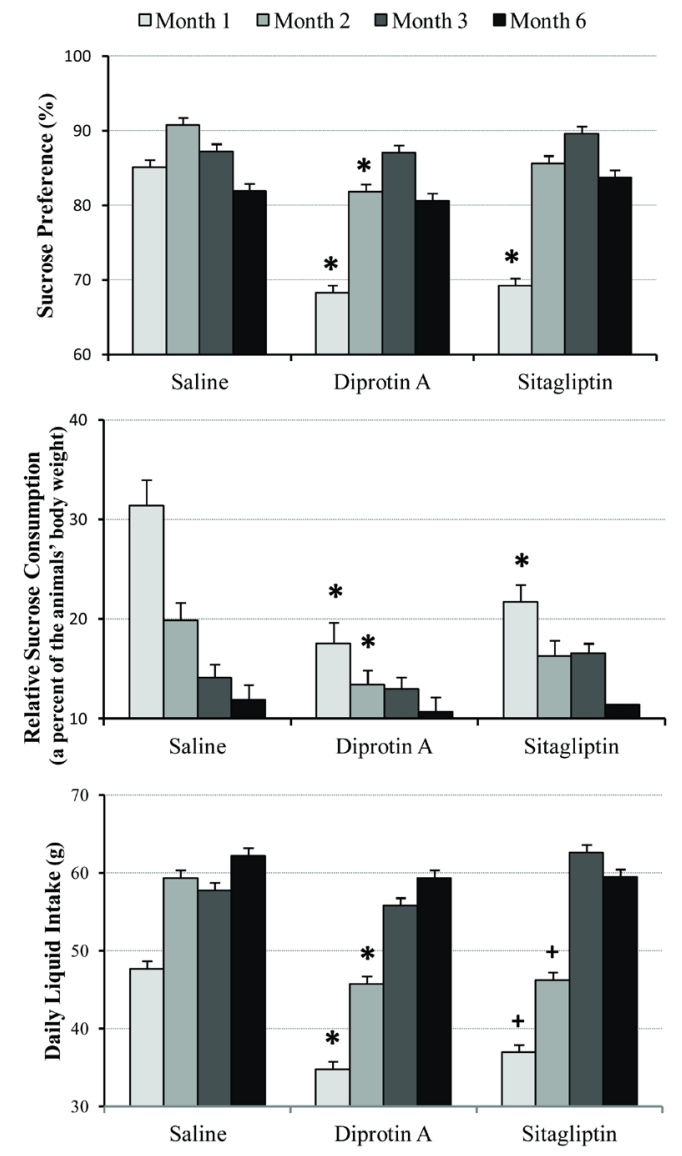

Figure 4. Preference for sucrose over water, relative sucrose consumption and daily liquid intake in rats that were postnatally exposed to the DPP-IV inhibitors diprotin A and sitagliptin. The ${ }^{*}$ indicates a statistically significant difference compared to the control (saline-treated) group, $\mathrm{p}<0.05$; the ${ }^{+}$indicates $\mathrm{p}<0.08$ compared to the controls (Kruskal-Wallis ANOVA followed by post hoc multiple comparisons analyses of the mean ranks). 
from the diprotin A-treated group exhibited a decrease in sucrose preference $[\mathrm{H}(2, \mathrm{~N}=59)=6.076, \mathrm{p}<0.05]$ and relative sucrose consumption [H $(2, \mathrm{~N}=59)=7.175, \mathrm{p}<0.03]$ (Figure 4). In addition, we continued to observe a decrease in the daily liquid intake in both experimental groups [H $(2, \mathrm{~N}=59)=6.204, \mathrm{p}<0.05]$ (Figure 4). However, similar to the one-month-old animals, the decrease did not reach statistical significance in the sitagliptin-treated rats. At the ages of three and six months, the rats treated with DPP-IV inhibitors did not exhibit symptoms of anhedonia or a reduction in the daily liquid intake.

The Friedman ANOVA analysis did not reveal a difference in sucrose preference of the one- to threemonth-old control rats: Chi-squared test $(\mathrm{N}=20, \mathrm{df}=2)=4.300, \mathrm{p}=0.116$. The diprotin A- and sitagliptintreated rats showed a gradual increase in sucrose preference up to the control level from one to three months of age: the Friedman ANOVA, Chi-squared test $(\mathrm{N}=17, \mathrm{df}=2)=12.118, \mathrm{p}<0.01$ and Chi-squared test $(\mathrm{N}=22$, $\mathrm{df}$ $=2$ ) $=18.909, p \leq 0.001$, respectively. The post hoc analysis revealed a difference between the preference values in the two- and three-month-old rats compared to the one-month-old rats in each experimental group (for all comparisons $\mathrm{p}<0.02$ ).

The relative sucrose consumption of the control group gradually decreased with age [the Friedman ANOVA, Chi-squared test $(\mathrm{N}=20, \mathrm{df}=2)=22.500, \mathrm{p}<0.001]$. The value of this parameter in the two-month-old rats was lower than in the one-month-old animals; it was also lower in the three-month-old rats than in the one- and two-month-old rats (for all comparisons $\mathrm{p}<0.01$ ). The sitagliptin-treated animals also demonstrated a decrease in their relative sucrose consumption [the Friedman ANOVA, Chi-squared test $(\mathrm{N}=22, \mathrm{df}=2)=15.545, \mathrm{p}<$ 0.001]. The relative sucrose consumption of the one-month-old rats exceeded the consumption of two- and three-month-old rats (in both cases $\mathrm{p}<0.01$ ). However, unlike the control animals, there was no difference between the values from the two- and three-month-old rats. The Friedman ANOVA analysis did not reveal a difference in the relative sucrose consumption of the one- to three-month-old rats treated with diprotin A: Chisquared test $(\mathrm{N}=20, \mathrm{df}=2)=0.824, \mathrm{p}=0.662$.

According to the Friedman ANOVA, there were no significant changes in the daily liquid intake of the control group from month 1 to month 3 [Chi-squared test $(\mathrm{N}=20, \mathrm{df}=2)=5.564, \mathrm{p}=0.062$ ] (Figure 4). At the same time, the diprotin A- and sitagliptin-treated animals did exhibit changes. The daily liquid intake increased in both groups: diprotin A-treated group: Chi-squared test $(\mathrm{N}=17, \mathrm{df}=2)=16.353, \mathrm{p}<0.001$; and sitagliptin-treated group: Chi-squared test $(\mathrm{N}=22, \mathrm{df}=2)=22.828, \mathrm{p}<0.001$. The consumption gradually increased from the first to the third month in both experimental groups. The post hoc Wilcoxon matched pairs test with FDR control confirmed a statistically significant increase in the daily fluid intake of the two-month-old rats compared to the one-month-old animals and of the three-month-old rats compared to the two-month-old animals (for all comparisons $\mathrm{p}<0.001$ ).

\subsection{Effects of Neonatal Diprotin A and Sitagliptin Exposure on Rats' Behavior in the Social Contact Test}

At the age of one month, only the diprotin A-treated rats showed increased aggression. The time spent in aggressive social contacts was increased $[\mathrm{H}(2, \mathrm{~N}=24)=8.054, \mathrm{p}<0.02]$, whereas the total number of non-aggressive social contacts $[\mathrm{H}(2, \mathrm{~N}=24)=7.024, \mathrm{p}<0.03]$ and time spent in non-aggressive contacts $[\mathrm{H}(2, \mathrm{~N}=$ $24)=6.142, p<0.05]$ were decreased. The results of the post hoc analysis are shown in Figure 5.

At the age of two months, both the diprotin A- and sitagliptin-treated animals demonstrated an increase in the total number of aggressive contacts $[\mathrm{H}(2, \mathrm{~N}=21)=10.213, \mathrm{p}<0.01]$ and in the time spent in aggressive contacts $[\mathrm{H}(2, \mathrm{~N}=21)=11.941, \mathrm{p}<0.01]$ (Figure 5). In addition, the diprotin A-treated rats exhibited a significant decrease in the latency to the first aggressive contact $[\mathrm{H}(2, \mathrm{~N}=21)=10.196, \mathrm{p}<0.01]$ (Table 3). These rats also exhibited a reduced number of the non-aggressive social contacts $[\mathrm{H}(2, \mathrm{~N}=21)=6.897, \mathrm{p}<0.04]$ and the time spent in such contacts $[\mathrm{H}(2, \mathrm{~N}=21)=11.016, \mathrm{p}<0.01]$ compared to the controls.

At the age of three months, aggression remained statistically significant only in the diprotin A-treated rats. The animals demonstrated an increased number of total aggressive contacts $[\mathrm{H}(2, \mathrm{~N}=20)=6.030, \mathrm{p}<0.05]$ and spent more time in aggressive contacts $[\mathrm{H}(2, \mathrm{~N}=20)=8.653, \mathrm{p}<0.02]$ (see Figure 5). The latency to the first aggressive contact was slightly decreased $[\mathrm{H}(2, \mathrm{~N}=20)=6.226, \mathrm{p}<0.05]$ (see Table 3 ). The KruskalWallis ANOVA also revealed a decrease in the number of non-aggressive social contacts $[\mathrm{H}(2, \mathrm{~N}=20)=$ 11.864, $\mathrm{p}<0.01]$ and in the time spent in the contacts [H $(2, \mathrm{~N}=20)=13.062, \mathrm{p}<0.01]$. The six-month-old rats did not differ in their social interactions.

Because the pairs used for the analysis of social interaction in each test were formed by different animals, the 

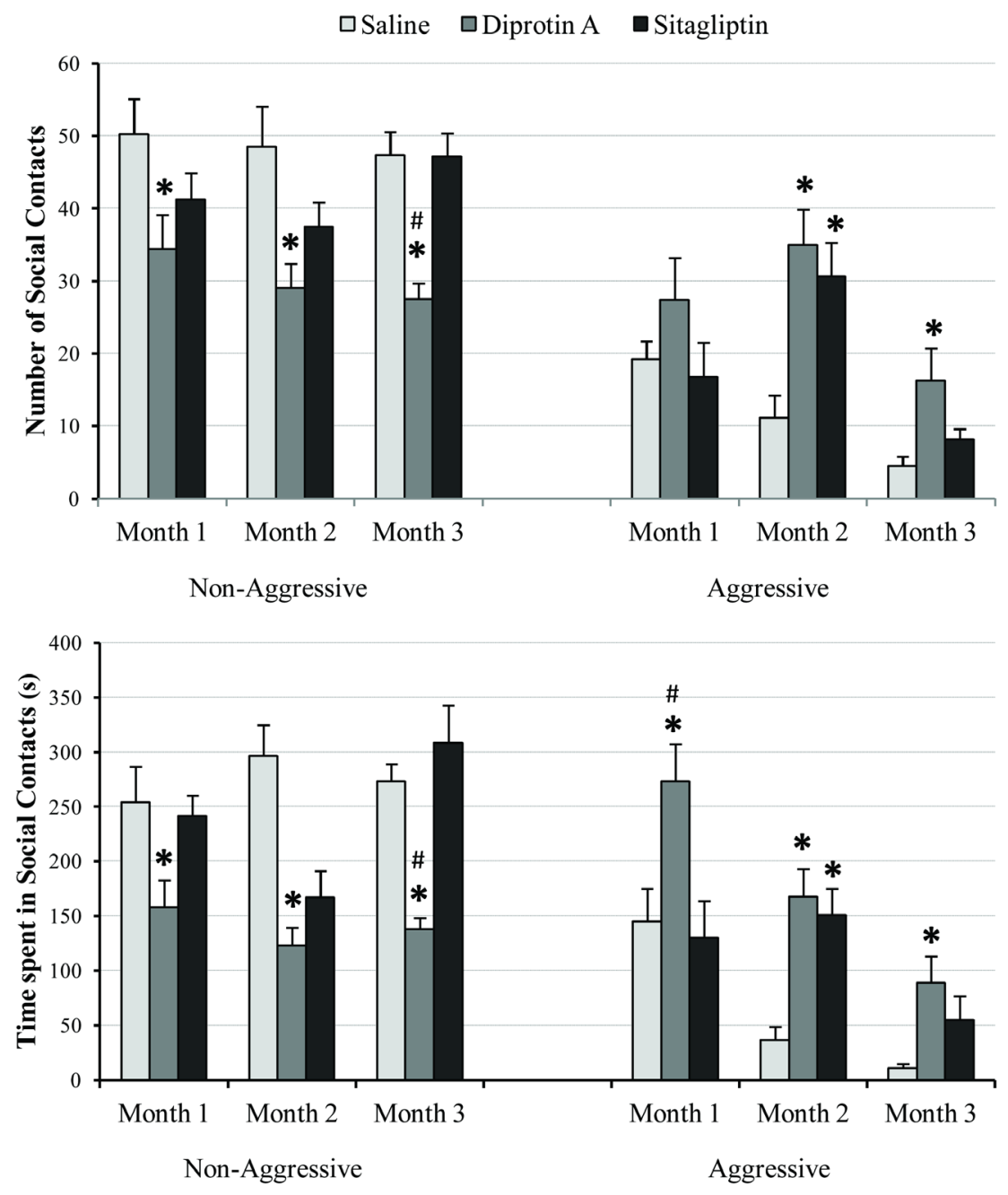

Figure 5. Effects of postnatally administered diprotin A and sitagliptin on aggressive and non-aggressive social contacts in rats. The number of pairs of diprotin A-treated rats was 7, 7, and 8 at the ages of one, two and three months, respectively; the number of pairs of sitagliptin-treated rats was 9, 8 and 6, respectively; and 8, 6 and 6, respectively, for the saline-treated rats. The ${ }^{*}$ indicates a statistically significant difference compared to the control (saline-treated) group, $\mathrm{p}<0.05$; the ${ }^{\#}$ indicates a statistically significant difference compared to the sitagliptin-treated group, $\mathrm{p}<0.05$ (Kruskal-Wallis ANOVA followed by post hoc multiple comparisons analyses of the mean ranks).

Table 3. Latency to the first aggressive contact (s) in rats treated with diprotin A and sitagliptin in the early postnatal period.

\begin{tabular}{ccc}
\hline Groups & Two-month-old rats & Three-month-old rats \\
\hline Diprotin A & $65.6 \pm 6.4^{* \#}$ & $192.8 \pm 85.4^{+}$ \\
Sitagliptin & $174.8 \pm 38.0$ & $334.2 \pm 61.7$ \\
Saline & $213.8 \pm 57.4$ & $453.3 \pm 103.2$
\end{tabular}

The ${ }^{*}$ indicates statistically significant difference compared to the control group (saline-treated rats), $\mathrm{p}<0.05$; the ${ }^{\#}$ indicates statistically significant difference compared to the sitagliptin-treated group, $\mathrm{p}<0.05$; the ${ }^{+}$indicates $\mathrm{p}=0.056$ compared to the controls (Kruskal-Wallis ANOVA followed by post hoc multiple comparisons analyses of the mean ranks). Values are given as mean \pm SEM (standard error of the mean).

analysis of the within-subject factor (age) effect was not performed.

\section{Discussion}

This study is the first to compare the effects of the well-known DPP-IV inhibitors diprotin A and sitagliptin on 
emotional and motivational behavior in rats after subchronic intraperitoneal administration of the drugs in the early postnatal period. Previously, we have shown that postnatal methionyl-2(S)-cyano-pyrrolidine, a synthetic non-competitive irreversible inhibitor of DPP-IV, causes anxiety- and depression-related behaviors in adolescent and adult rats (from the first to the seventh month) [29] [47]. In the present study, we have demonstrated that rat pups exposed to DPP-IV inhibitors with different mechanisms of action in the early postnatal period might develop persistent behavioral disorders.

Sitagliptin and diprotin A, unlike methionyl-2(S)-cyano-pyrrolidine, are reversible DPP-IV inhibitors that bind to the enzyme with a non-covalent bond. Although they have different binding interfaces on the active site of the enzyme, these DPP-IV inhibitors have similar features in their molecular interactions with the DPP-IV target through three common amino acids (Glu205, Glu206, and Try226) involved in H-bond formation and several residues involved in hydrophobic interactions [48]. The consequences of postnatal administration of these DPP-IV inhibitors were similar in principle, but differ in the details.

Both the one-month-old diprotin A- and sitagliptin-treated rats demonstrated signs of increased anxiety in the EPM, based on an increased preference for the closed arms. However, only diprotin A led to a marked reduction in the preference for the open arms, while sitagliptin increased the latency to the risk-assessment behavior. The diprotin A-treated rats exhibited increased anxiety, as demonstrated by their anxiety-phobic score at the age of one month. Hence, the diprotin A-treated rats showed more pronounced anxiety compared to sitagliptin-treated animals using the present scheme of DPP-IV inhibitor administration.

Although there were no differences in animals' locomotor activity in the EPM, the two-month-old diprotin Aand sitagliptin-treated rats did increase their exploratory activity (see Table 2). It is worth noting that the rats exhibited increased exploratory activity when their anxiety levels had returned to normal. The data agree with the inverse relationship between anxiety and exploratory activity [49].

Based on the view that grooming takes place during de-arousal after a stressful experience [39], one could propose that the two-month-old diprotin A- and sitagliptin-treated animals exhibited increased emotional tension. Judging by the increase in the number of grooming episodes in the sitagliptin-treated rats and reduced latency to the first episode in the diprotin A-treated rats compared to the controls, the signs of increased emotional tension were maintained in three-month-old animals.

We believe that the decrease in sucrose preference and relative sucrose consumption caused by the DPP-IV inhibitors indicates a decrease in one of the vital motivations to experience pleasure, i.e., anhedonia. At the age of one month, both the diprotin A- and sitagliptin-treated rats showed signs of anhedonia, whereas, at the age of two months, only the diprotin A-treated rats still showed the symptoms of decreased motivation to experience pleasure (see Figure 4). The results testified to the greater efficiency of diprotin A in the induction of depressive-like behaviors. It is noteworthy that the decrease in drinking motivation, another vital motivation, was only significant in the diprotin A-treated rats (see Figure 4).

In principal, both sitagliptin and diprotin A may affect glucose metabolism by enhancing the incretin axis, followed by a reduction in the blood glucose levels [33] that might lead to the changes in sucrose preference and consumption as symptoms of anhedonia. Although we did not evaluate the blood glucose and incretin levels in the present study, we controlled the level of blood glucose in our previous study in a rat model of anxiety-depression disorder induced by the postnatal administration of the DPP-IV inhibitor methionyl-2(S)-cyanopyrrolidine and did not observe changes [unpublished data]. We will obtain clear evidence of the nature of the decrease in sucrose preference and consumption in future studies of antidepressants and biochemical control.

The results from the FST support the conclusion that administration of the DPP-IV inhibitors in the early postnatal period may induce depressive-like behavior in rats. This test showed the strongest differences in the behaviors of the rats treated with the different DPP-IV inhibitors. According to the data, only the diprotin A-treated animals demonstrated a depressive-like behavior at two months, which was revealed as a reduced ability to escape the aversive situation. It is worth noting that weak symptoms of depressive-like behavior remained in the three-month-old rats, when they did not exhibit reduced sucrose preference and consumption. In contrast, the putative alterations in the blood glucose levels in the sitagliptin-treated rats were not manifested as depression-like behaviors in the FST. If we assume that depressive-like behaviors are associated with changes in glucose metabolism, various tests must detect this behavior at the same time. Thus, it is unlikely that the observed changes are due to glucose metabolism. Instead, they are likely based on the other mechanisms.

On the whole, neonatal administration of diprotin A caused a more pronounced reduction of vital motivations than sitagliptin, thus having a stronger depression-like effect. 
We only obtained evidence of reduced motivation for non-aggressive social contacts for the diprotin A-treated rats over a three month period (see Figure 5). This result agrees with the conclusion that this DPP-IV inhibitor exhibits a stronger depression-like effect. The reduction in the number of social contacts was not explained by an increase in anxiety [49] because the two- and three-month-old diprotin A-treated rats did not exhibit anxiety. Nevertheless, the relationship between the social avoidance and the depression-like behavior in the diprotin A-treated rats should be investigated further using chronic antidepressant treatments.

Of particular interest are the aggressive behaviors in the social contact test. Markedly increased aggression was observed in the diprotin A-treated rats over three months, whereas sitagliptin-treated rats only showed an increase at the age of two months. Thus, the animals treated with the different DPP-IV inhibitors develop different susceptibilities to aggression under mild isolation stress.

By comparing the appearance and maintenance of the behavioral disorders in the diprotin A- and sitagliptintreated, we concluded that, in this study, diprotin A caused more pronounced and long-term consequences, which are comparable to the effects of methionyl-2(S)-cyano-pyrrolidine [29]. The latter inhibitor was used at a dose of $1 \mathrm{mg}$ per kg at the same time points with an approximately equimolar amount (MW 199.27). The neurobiology of the relationship between the emotional and motivational disturbances mentioned above is not clear, although the behavioral alterations have a common trigger, namely DPP-IV inhibition in the early postnatal period. Based on this study, we believe that these disorders may share a common etiology in some cases.

In the present study, we did observe a reduced weight gain in the sitagliptin-treated rats within the first three months of the survey. At first glance, the data do not agree with the data on the absence of changes in body mass index in patients with type 2 diabetes mellitus after 48 months of treatment with the clinically recommended dose of sitagliptin to achieve lower postprandial hyperglycemia [33]. Moreover, chronic sitagliptin administration at a dose of $50 \mathrm{mg} / \mathrm{kg}$ did not have an effect on body weight in mice fed a high-fat diet [50]. However, when comparing these findings, we should remember that the sitagliptin administration began in early ontogeny in the present study. Therefore, we have a reason to believe that sitagliptin interferes with the process of the physical development in the early postnatal period. Rats with an inactive, mutant form of DPP-IV displayed reduced body weights, along with behavioral disorders [51]. Reduced levels of DPP-IV are detected in the blood of patients suffering from bulimia and anorexia nervosa, suggesting that DPP-IV and its substrates might take part in the regulation of feeding behavior [52]. Our findings reveal that sitagliptin may be a putative regulator of eating behavior. We suggest that the disturbances in the emotional and motivational behavior in DPP-IV inhibitor-treated animals, as well as the delay in body weight gain in the sitagliptin-treated rats, may be due to the developmental changes in DPP-IV expression [28]. These changes might alter the degradation of various peptides [32] [53], including neuropeptide Y, substance P, peptide YY [14] [18] [51] [54], which may be directly or indirectly related to anxiety, aggression, feeding and depression-like behavior. However, this assumption is hardly exhaustive. In our experiments, the rats were exposed to the DPP-IV inhibitors during the maturation of the DPP-IV enzyme system [28]. As stated above, we have unexpectedly revealed a steady increase in the activity of DPP-IV in the brain structures in rats with anxiety- and depression-related behaviors induced by the synthetic DPP-IV inhibitor methionyl-2(S)-cyano-pyrrolidine in the early postnatal period [31]. The changes in enzyme activity are most likely the result of epigenetic regulation when a long-acting DPP-IV inhibitor is administered in the early postnatal period. To prove this assumption, we plan to determine whether the expression of the DPP-IV gene changes in the brain structures isolated from the diprotin A- and sitagliptin-treated rats in the neonatal period. A recent study has shown that the effects of at least one of the DPP-IV inhibitors, sitagliptin, on cognitive activity are associated with a significant up-regulation of the expression of hippocampal genes [50]. Therefore, changes in gene expression in the CNS may be responsible for the behavioral effects of the DPP-IV inhibitors.

Recently, Sharma et al. [55] have shown that acute administration of sitagliptin caused anxiolytic effects in adult rats tested in the EPM. These data do not seem to agree with the results of the present work. However, an anxiolytic effect was observed at a dose of $20 \mathrm{mg} / \mathrm{kg}$ sitagliptin, when the drug was administered in a single dose. The dose of $5 \mathrm{mg} / \mathrm{kg}$, which is comparable to that used in our work (4 mg/kg), had no anxiolytic effects. Apparently, the effects of sitagliptin depend on the dose of the drug, the method, and duration of administration, as well as the ontogeny of the rats.

\section{Conclusion}

In general, systemic administration of the DPP-IV inhibitors diprotin A and sitagliptin in the early postnatal pe- 
riod alters the emotional and motivational behaviors of adolescent and adult rats. Diprotin A exhibits a more significant impact on the animals' behaviors compared to sitagliptin. We believe that the behavioral disturbances induced by the DPP-IV inhibitors can be used as putative models of mixed anxiety-depression-like disorders with disinhibited aggression upon mild stress provocation. Additionally, the data from the present study demonstrate the involvement of DPP-IV in the genesis of emotional and motivational disorders.

\section{Limitations}

One of the main limitations of this study is that the late effects of inhibitors of DPP-IV were studied in the only period of their administration-PND 5-18. Another limitation is the use of only one dose of each of the inhibitors of DPP-IV. In the present study, blood glucose and incretin levels were not examined at various time points of ontogeny after the administration of the DPP-IV inhibitors in the early postnatal period. We suppose further researches to be performed to ascertain whether neonatal modulation of DPP-IV activity contributes to the genesis of emotional and motivational disorders and through which mechanisms.

\section{Acknowledgements}

We thank Ms. Sofiya Semenyuk and Mrs. Polina Mavrenkova, the students of the Faculty of Psychology, Lomonosov Moscow State University, who kindly assisted in providing the data necessary for the analysis.

\section{Role of the Funders}

These studies were supported by the Russian Foundation for Basic Research (RFBR) (grant number: 15-0408784). The RFBR had no role in the design, implementation, analysis, or interpretation of the data, in the preparation of the manuscript, or in the decision to submit the paper for publication. None of the material in this paper has been submitted for publication elsewhere.

\section{Conflicts of Interest}

The authors have no conflicts of interest to declare.

\section{References}

[1] Millan, M.J. (2006) Multi-Target Strategies for the Improved Treatment of Depressive States: Conceptual Foundations and Neuronal Substrates, Drug Discovery and Therapeutic Application. Pharmacology \& Therapeutics, 110, 135-370. http://dx.doi.org/10.1016/j.pharmthera.2005.11.006

[2] Lasoń, W., Budziszewska, B., Basta-Kaim, A., Kubera, M. and Maes, M. (2013) New Trends in the Neurobiology and Pharmacology of Affective Disorders. Pharmacological Reports, 65, 1441-1450. http://dx.doi.org/10.1016/S1734-1140(13)71504-4

[3] Chioqueta, A.P. and Stiles, T.C. (2003) Suicide Risk in Outpatients with Specific Mood and Anxiety Disorders. Crisis, 24, 105-112. http://dx.doi.org/10.1027//0227-5910.24.3.105

[4] Kohn, S.R. and Asnis, G. M. (2003) Aggression in Psychiatric Disorders. In: Mattson, M.P., Ed., Neurobiology of Aggression: Understanding and Preventing Violence. Humana Press Inc., Totowa, NJ, 135-149. http://dx.doi.org/10.1385/1-59259-382-8:135

[5] Neumann, I.D., Veenema, A.H. and Beiderbeck, D.I. (2010) Aggression and Anxiety: Social Context and Neurobiological Links. Frontiers in Behavioral Neuroscience, 4, 12.

[6] (2013) American Psychiatric Association: Diagnostic and Statistical Manual of Mental Disorders. 5th Edition, DSM-5 ${ }^{\mathrm{TM}}$, American Psychiatric Publishing, Arlington, VA. http://dsm.psychiatryonline.org/

[7] Swann, A.C. (2003) Neuroreceptor Mechanisms of Aggression and its Treatment. The Journal of Clinical Psychiatry, 64, 26-35. http://www.psychiatrist.com/JCP/article/Pages/2003/v64s04/v64s0404.aspx

[8] Villanueva, R. (2013) Neurobiology of Major Depressive Disorder. Neural Plasticity, 2013, Article ID: 873278, 7 p.

[9] Martin, E.I., Ressler, K.J., Binder, E. and Nemeroff C.B. (2009) The Neurobiology of Anxiety Disorders: Brain Imaging, Genetics, and Psychoneuroendocrinology. Psychiatric Clinics of North America, 32, 549-575. http://dx.doi.org/10.1016/j.psc.2009.05.004

[10] Siever, L.J. (2008) Neurobiology of Aggression and Violence. The American Journal of Psychiatry, 165, 429-442. http://dx.doi.org/10.1176/appi.ajp.2008.07111774 
[11] Yanowitch, R. and Coccaro, E.F. (2011) Chapter 7-The Neurochemistry of Human Aggression. Advances in Genetics, 75, 151-169. http://dx.doi.org/10.1016/B978-0-12-380858-5.00005-8

[12] Patki, G., Atrooz, F., Alkadhi, I., Solanki, N. and Salim, S. (2015) High Aggression in Rats Is Associated with Elevated Stress, Anxiety-Like Behavior, and Altered Catecholamine Content in the Brain. Neuroscience Letters, 584, 308-313. http://dx.doi.org/10.1016/j.neulet.2014.10.051

[13] Walker, A.J., Kim, Y., Price, J.B., Kale, R.P., McGillivray, J.A., Berk, M. and Tye, S.J. (2014) Stress, Inflammation, and Cellular Vulnerability during Early Stages of Affective Disorders: Biomarker Strategies and Opportunities for Prevention and Intervention. Frontiers in Psychiatry, 5, 34. http://dx.doi.org/10.3389/fpsyt.2014.00034

[14] Heim, C., Plotsky, P.M. and Nemeroff, C.B. (2004) Importance of Studying the Contributions of Early Adverse Experience to Neurobiological Findings in Depression. Neuropsychopharmacology, 29, 641-648. http://dx.doi.org/10.1038/sj.npp.1300397

[15] Hansson, S.R., Hoffman, B.J. and Mezey, E. (1998) Ontogeny of Vesicular Monoamine Transporter mRNAs VMAT1 and VMAT2. I. The Developing Rat Central Nervous System. Developmental Brain Research, 110, 135-158. http://dx.doi.org/10.1016/S0165-3806(98)00104-7

[16] Ugryumov, M.V. (2000) The Differentiation of Dopaminergic Neurons in Situ, in Vivo, and in Transplants. Neuroscience and Behavioral Physiology, 30, 37-43. http://dx.doi.org/10.1007/BF02461390

[17] Shabanov, P.D., Lebedev, A.A. and Nozdrachev, A.D. (2002) Critical Periods of the Dopaminergic System Formation in Rat Brain. Doklady Biological Sciences, 386, 421-425. http://dx.doi.org/10.1023/A:1020758100186

[18] Catena-Dell’Osso, M., Fagiolini, A., Marazziti, D., Baroni, S. and Bellantuono, C. (2013) Non-Monoaminergic Targets for the Development of Antidepressants: Focus on Neuropeptides. Mini Reviews in Medicinal Chemistry, 13, 2-10. http://dx.doi.org/10.2174/138955713804484758

[19] Díaz, C., Morales-Delgado, N. and Puelles, L. (2015) Ontogenesis of Peptidergic Neurons within the Genoarchitectonic Map of the Mouse Hypothalamus. Frontiers in Neuroanatomy, 8, 162.

[20] Vanhoof, G., Goossens, F., De Meester, I., Hendriks, D. and Scharpé, S. (1995) Proline Motifs in Peptides and Their Biological Processing. Federation of American Societies for Experimental Biology Journal, 9, 736-744. http://www.fasebj.org/content/9/9/736.full.pdf

[21] Maes, M. and Bonaccorso, S. (2004) Lower Activities of Serum Peptidases Predict Higher Depressive and Anxiety Levels Following Interferon-Alpha-Based Immunotherapy in Patients with Hepatitis C. Acta Psychiatrica Scandinavica, 109, 126-131. http://dx.doi.org/10.2174/138955713804484758

[22] Deng, J., Lamb, J.R., McKeown, A.P., Miller, S., Muglia, P., Guest, P.C., Bahn, S., Domenici, E.H. and Rahmoune, H. (2013) Identification of Altered Dipeptidyl-Peptidase Activities as Potential Biomarkers for Unipolar Depression. Journal of Affective Disorders, 151, 667-672. http://dx.doi.org/10.1016/j.jad.2013.07.015

[23] El Yacoubi, M., Vaugeois, J., Marguet, D., Sauze, N., Guieu, R., Costentin, J. and Fenouillet, E. (2006) Behavioral Characterization of CD26 Deficient Mice in Animal Tests of Anxiety and Antidepressant-Like Activity. Behavioural Brain Research, 171, 279-285. http://dx.doi.org/10.1016/j.bbr.2006.04.003

[24] Frerker, N., Raber, K., Bode, F., Skripuletz, T., Nave, H., Klemann, C., Pabst, R., Stephan, M., Schade, J., Brabant, G., Wedekind, D., Jacobs, R., Jörns, A., Forssmann, U., Straub, R.H., Johannes, S., Hoffmann, T., Wagner, L., Demuth, H.U. and von Hörsten, S. (2009) Phenotyping of Congenic Dipeptidyl Peptidase 4 (DP4) Deficient Dark Agouti (DA) Rats Suggests Involvement of DP4 in Neuro-, Endocrine, and Immune Functions. Clinical Chemistry and Laboratory Medicine, 47, 275-287. http://dx.doi.org/10.1515/CCLM.2009.064

[25] Krupina, N.A., Zolotov, N.N., Bogdanova, N.G., Orlova, I.N., Khlebnikova, N.N. and Kryzhanovskii, G.N. (2006) Activities of Prolyl Endopeptidase and Dipeptidyl Peptidase IV in Brain Structures of Rats with Dopamine Deficiency-Dependent MPTP-Induced Depressive Syndrome. Bulletin of Experimental Biology and Medicine, 142, 554-556. http://dx.doi.org/10.1007/s10517-006-0416-5

[26] Krupina, N.A., Bogdanova, N.G., Khlebnikova, N.N., Zolotov, N.N. and Kryzhanovskii, G.N. (2013) Benzyloxycarbonyl-methionyl-2(S)-cyanopyrrolidine, a Prolyl Endopeptidase Inhibitor, Modulates Depression-Like Behavior of Rats in Forced Swimming Test and Activities of Proline-Specific Peptidases in the Brain Structures. Bulletin of Experimental Biology and Medicine, 154, 606-609. http://dx.doi.org/10.1007/s10517-013-2010-y

[27] Kato, T., Hama, T., Nagatsu, T., Kuzuya, Y. and Sakakibara, S. (1979) Changes of X-Prolyl Dipeptidyl-Aminopeptidase Activity in Developing Rat Brain. Experientia, 35, 1329-1330. http://dx.doi.org/10.1007/bf01963989 http://link.springer.com/article/10.1007/BF01963989

[28] Brust, P., Bech, A., Kretzschmar, R. and Bergmann, R. (1994) Developmental Changes of Enzymes Involved in Peptide Degradation in Isolated Rat Brain Microvessels. Peptides, 15, 1085-1088. http://dx.doi.org/10.1016/0196-9781(94)90074-4

[29] Krupina, N.A., Kushnareva, E.Y., Khlebnikova, N.N., Zolotov, N.N. and Kryzhanovskii, G.N. (2009) Behavioral 
Changes in Rats Induced by a Dipeptidyl Peptidase IV Inhibitor Methionyl-2(S)-cyanopyrrolidine: Experimental Model of Anxiety-Depression Disorder. Bulletin of Experimental Biology and Medicine, 147, 285-290. http://dx.doi.org/10.1007/s10517-009-0493-3

[30] Khlebnikova, N.N., Kushnareva, E.Y., Krupina, N.A. and Rodina, V.I. (2011) Novel Synthetic Inhibitor of Dipeptidyl Peptidase IV Methionyl-2(S)-cyanopyrrolidine Induces Latent Aggression in Rats. European Neuropsychopharmacology, 21, S302. http://dx.doi.org/10.1016/s0924-977x(11)70477-1

[31] Khlebnikova, N.N., Krupina, N.A., Kushnareva, E.Y., Zolotov, N.N. and Kryzhanovskii, G.N. (2012) Effect of Imipramine and Prolyl Endopeptidase Inhibitor Benzyloxycarbonyl-methionyl-2(S)-cyanopyrrolidine on Activity of Proline-Specific Peptidases in the Brain of Rats with Experimental Anxious-Depressive Syndrome. Bulletin of Experimental Biology and Medicine, 152, 409-412. http://dx.doi.org/10.1007/s10517-012-1540-z

[32] McIntosh, C.H., Demuth, H.U., Kim, S.J., Pospisilik, J.A. and Pederson, R.A. (2006) Applications of Dipeptidyl Peptidase IV Inhibitors in Diabetes Mellitus. International Journal of Biochemistry and Cell Biology, 38, 860-872. http://dx.doi.org/10.1016/j.biocel.2005.12.013

[33] Hsieh, C.J. and Shen, F.C. (2014) The Durability of Sitagliptin in Elderly Patients with Type 2 Diabetes. Clinical Interventions in Aging, 9, 1905-1911. http://dx.doi.org/10.2147/CIA.S72396

[34] Broxmeyer, H.E. and Pelus, L.M. (2014) Inhibition of DPP4/CD26 and dmPGE2 Treatment Enhances Engraftment of Mouse Bone Marrow Hematopoietic Stem Cells. Blood Cells, Molecules, and Diseases, 53, 34-38. http://dx.doi.org/10.1016/j.bcmd.2014.02.002

[35] Guskova, T.A. (2010) Preclinical Toxicological Study of Drugs as a Guarantee of Their Safe Clinical Investigations. Toksikologicheskiŭ Vestnik, 5, 2-5. http://en.toxreview.ru/magazine/?c4a=20100500

[36] Walf, A.A. and Frye, C.A. (2007) The Use of the Elevated plus Maze as an Assay of Anxiety-Related Behavior in Rodents. Nature Protocols, 2, 322-328. http://dx.doi.org/10.1038/nprot.2007.44

[37] Ennaceur, A. (2014) Tests of Unconditioned Anxiety-Pitfalls and Disappointments. Physiology and Behavior, 135, 55-71. http://dx.doi.org/10.1016/j.physbeh.2014.05.032

[38] O’Leary, T.P., Gunn, R.K. and Brown, R.E. (2013) What Are We Measuring When We Test Strain Differences in Anxiety in Mice? Behavior Genetics, 43, 34-50.

[39] Estanislau, C. (2012) Cues to the Usefulness of Grooming Behavior in the Evaluation of Anxiety in the Elevated Plus-Maze. Psychology \& Neuroscience, 5, 105-112. http://dx.doi.org/10.3922/j.psns.2012.1.14

[40] Porsolt, R.D., Anton, G., Blavet, N. and Jalfre, M. (1978) Behavioral Despair in Rats: A New Model Sensitive to Antidepressant Treatments. European Journal of Pharmacology, 47, 379-391. http://dx.doi.org/10.1016/0014-2999(78)90118-8

[41] Overstreet, D.H., Pucilowski, O., Rezvani, A.H. and Janowsky, D.S. (1995) Administration of Antidepressants, Diazepam and Psychomotor Stimulants Further Confirms the Utility of Flinders Sensitive Line Rats as an Animal Model of Depression. Psychopharmacology, 121, 27-37. http://dx.doi.org/10.1007/BF02245589

[42] Kryzhanovskii, G.N., Krupina, N.A. and Kucheryanu, V.G. (1995) A New Model of the Depressive Syndrome Induced by Administration of 1-Methyl-4-phenyl-1,2,3,6-tetrahydropyridine (MPTP) in Rats. Bulletin of Experimental Biology and Medicine, 119, 116-119. http://dx.doi.org/10.1007/BF02445853

[43] Shchetinin, E.V., Baturin, V.A., Arushanian, E.B., Ovanesov, K.B. and Popov, A.V. (1989) A Biorhythmologic Ap-

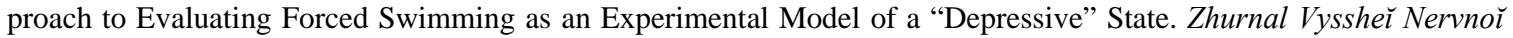
Deiatelnosti imeni IP Pavlova, 39, 958-964. http://elibrary.ru/item.asp?id=19109145

[44] Rodina, V.I., Krupina, N.A., Kryzhanovskii, G.N. and Oknina, N.B. (1992) A New Method of Evaluating Anxiety States and Phobias in Rats. Bulletin of Experimental Biology and Medicine, 114, 916-920. http://dx.doi.org/10.1007/BF00790041

[45] D’Aquila, P.S., Newton, J. and Willner, P. (1997) Diurnal Variation in the Effect of Chronic Mild Stress on Sucrose Intake and Preference. Physiology and Behavior, 62, 421-426. http://dx.doi.org/10.1016/S0031-9384(97)00042-5

[46] Benjamini, Y. and Hochberg, Y. (1995) Controlling the False Discovery Rate: A Practical and Powerful Approach to Multiple Testing. Journal of the Royal Statistical Society. Series B (Methodological), 57, 289-300. http://www.jstor.org/stable/2346101

[47] Kushnareva, E.Y., Krupina, N.A., Khlebnikova, N.N., Kudrin, V.S., Zolotov, N.N. and Kryzhanovskii, G.N. (2012) The Levels of Monoamines and Their Metabolites in the Brain Structures of Rats with an Experimental Anxiodepressive State Induced by Administration of Dipeptidyl Peptidase 4 in the Early Postnatal Period. Neurochemical Journal, 6, 29-37. http://dx.doi.org/10.1134/S1819712412010047

[48] Chakraborty, C., Hsu, M.J. and Agoramoorthy, G. (2014) Understanding the Molecular Dynamics of Type-2 Diabetes Drug Target DPP-4 and Its Interaction with Sitagliptin and Inhibitor Diprotin-A. Cell Biochemistry and Biophysics, 70, 907-922. http://dx.doi.org/10.1007/s12013-014-9998-0 
[49] File, S.E. and Seth, P. (2003) A Review of 25 Years of the Social Interaction Test. European Journal of Pharmacology, 463, 35-53. http://dx.doi.org/10.1016/S0014-2999(03)01273-1

[50] Gault, V.A., Lennox, R. and Flatt, P.R. (2015) Sitagliptin, a Dipeptidyl Peptidase-4 Inhibitor, Improves Recognition Memory, Oxidative Stress and Hippocampal Neurogenesis and Upregulates Key Genes Involved in Cognitive Decline. Diabetes, Obesity and Metabolism, 17, 403-413. http://dx.doi.org/10.1111/dom.12432

[51] Karl, T., Hoffmann, T., Pabst, R. and von Hörsten, S. (2003) Extreme Reduction of Dipeptidyl Peptidase IV Activity in F344 Rat Substrains is Associated with Various Behavioral Differences. Physiology and Behavior, 80, 123-134. http://dx.doi.org/10.1016/S0031-9384(03)00229-4

[52] Van West, D., Monteleone, P., Di Lieto, A., De Meester, I., Durinx, C., Scharpe, S., Lin, A., Maj, M. and Maes, M. (2000) Lowered Serum Dipeptidyl Peptidase IV Activity in Patients with Anorexia and Bulimia Nervosa. European Archives of Psychiatry and Clinical Neuroscience, 250, 86-92. http://dx.doi.org/10.1007/s004060070040

[53] Scharpé, S. and De Meester, I. (2001) Peptide Truncation by Dipeptidyl Peptidase IV: A New Pathway for Drug Discovery? Verhandelingen-Koninklijke Vlaamse Academie voor Geneeskunde van België, 63, 5-32. http://www.pubfacts.com/detail/11284388/Peptide-truncation-by-dipeptidyl-peptidase-IV-a-new-pathway-for-drug-dis covery

[54] Haller, J. (2013) The Neurobiology of Abnormal Manifestations of Aggression-A Review of Hypothalamic Mechanisms in Cats, Rodents, and Humans. Brain Research Bulletin, 93, 97-109. http://dx.doi.org/10.1016/j.brainresbull.2012.10.003

[55] Sharma, A.N., Pise, A., Sharma, J.N. and Shukla, P. (2015) Dipeptidyl-Peptidase IV (DPP-IV) Inhibitor Delays Tolerance to Anxiolytic Effect of Ethanol and Withdrawal-Induced Anxiety in Rats. Metabolic Brain Disease, 30, 659-667. http://dx.doi.org/10.1007/s11011-014-9603-7 